\title{
1,4-Sila- and stannatropic strategy for generation of 1,3-dipoles and its application to heterocyclic synthesis
}

\author{
Mitsuo Komatsu, ${ }^{* a}$ Satoshi Minakata, ${ }^{b}$ and Yoji Oderaotoshib \\ ${ }^{a}$ Department of Applied Chemistry, Center for Atomic and Molecular Technologies, Graduate \\ School of Engineering, Osaka University, Yamadaoka 2-1, Suita, Osaka 565-0871, Japan, \\ Research Center for Enviromental Preservation, Osaka University, Yamadaoka 2-4, Suita, \\ Osaka 565-0871, Japan \\ ${ }^{b}$ Department of Applied Chemistry, Graduate School of Engineering, Osaka University, \\ Yamadaoka 2-1, Suita, Osaka 565-0871, Japan \\ E-mail: komatsu@chem.eng.osaka-u.ac.jp
}

\begin{abstract}
We present herein effective generation and cycloaddition of azomethine ylides and azomethine imines utilizing 1,4-metallatropic strategy in this. Since the metallatropy are based on the strong affinity between silicon/tin and oxygen/sulfur, the method does not require any additives and bases for the generation of the dipoles, which can avoid limitations in the functional groups of starting materials and dipolarophiles in their cycloaddition. Moreover, the present method could realize the efficient generation of less- or non-stabilized 1,3-dipoles.
\end{abstract}

Keywords: Azomethine ylide, azomethine imine, 1,3-dipole, 1,4-metallatropy, cycloaddition

\section{Contents}

1. Introduction

2. Generation of Pyridinium Ylides from $N$-(Silylmethyl)pyridone Analogs via 1,4-Silatropy

3. Generation of Azomethine Ylides as Nitrile Ylide Equivalents from $N$ -

(Stannylmethyl)thioamides via 1,4-Stannatropy

4. Generation of Azomethine Imines from $\alpha$-Silylnitrosamines via 1,4-Silatropy and Their Cycloaddition 


\section{Introduction}

Heterocyclic compounds ${ }^{1}$ possess a structure which contains two or more different kinds of atoms in the ring. They are widely distributed in nature and play an important role for the maintenance of life. For example, proline, histidine, and tryptophan are essential amino acids. The pyrimidine and purine bases are constituent units of DNA which is a genetic material. The oxygen-transporting pigment hemoglobin and the photosynthesizing pigment chlorophyll are also heterocyclic. A number of heterocyclic compounds in nature possess pharmacological activities and some of these have been used for the treatment of diseases. Further, the most of the developed medicines are synthetic heterocycles. On the other hand, heterocycles are also important as key compounds for the agricultural chemicals, dye stuffs, photographic sensitizers and developers, antioxidants, vulcanization accelerators, and copolymers. Therefore, development of novel methods for the synthesis of heterocyclic compounds has been required.

1,3-Dipolar cycloaddition has been widely used for the synthesis of heterocyclic compounds because of its utility for creating two sets of bonds in a single operation and because stereoselectivity and regioselectivity are easily predictable. ${ }^{2}$ Among a number of 1,3-dipoles, azomethine ylides ${ }^{3}$ and azomethine imines ${ }^{4}$ are useful intermediates for the synthesis of various five-membered nitrogen-containing heterocycles. They belong to the class of 1,3-dipoles of the allyl type ${ }^{5}$ with a cationic nitrogen atom and react with several dipolarophiles to give pyrrolidine or pyrazolidine derivatives, respectively.

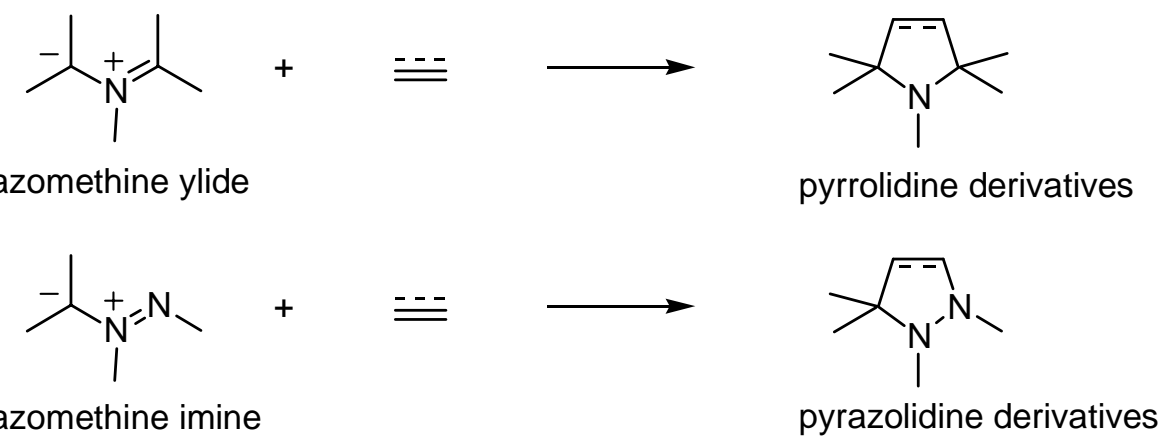

A number of researchers have developed practical and useful methods for the generation of azomethine ylides. One involves the ring opening of aziridines, ${ }^{6}$ which works well when the aziridine has an electron-withdrawing substituent on the carbon atom.

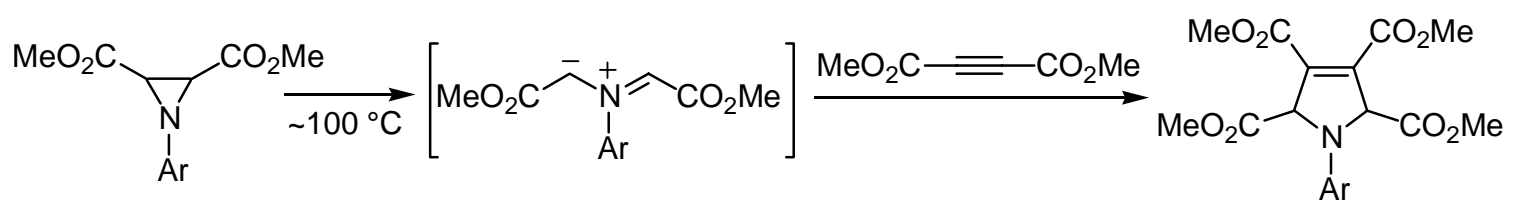

Another important method involves generation from $\alpha$-silylimine derivatives. ${ }^{3}$ This enables the generation of less-stabilized azomethine ylides, which lack $\alpha$-substituents to stabilize 
the negatively charged carbon, by taking advantage of the fact that carbon-silicon bonds are easily cleaved by nucleophiles such as halide ion. Thus, desilylation of $\alpha$-silyliminium salts, ${ }^{7}$ treatment of $\alpha$-silylimine derivatives with an acyl halide, ${ }^{8}$ trimethylsilyl triflate ${ }^{9}$ or trifluoroacetic acid, ${ }^{10}$ and the water-induced desilylation of $\alpha$-silylimine derivatives ${ }^{11}$ have been developed.

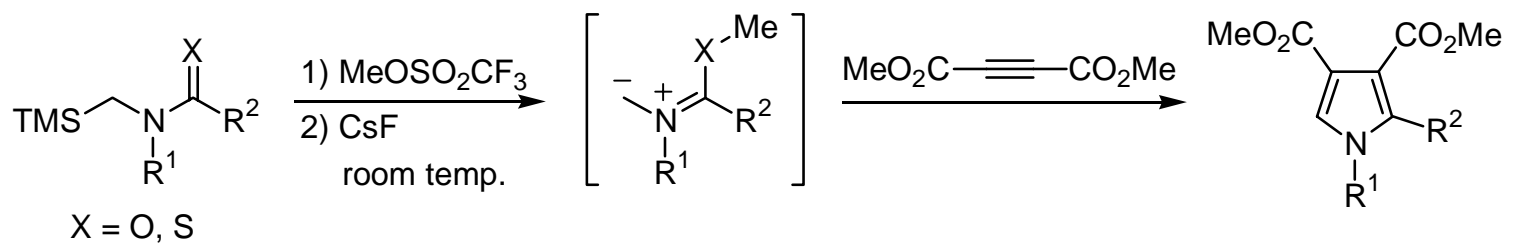

On the other hand, $N$-unsubstituted azomethine ylides exist as tautomers of $\alpha$-iminoester derivatives under thermal conditions. Namely, the highly acidic hydrogen adjacent to the imine migrates to the nitrogen. Thus generated azomethine ylides undergo 1,3-dipolar cycloaddition to give pyrrolidine derivatives. ${ }^{12}$

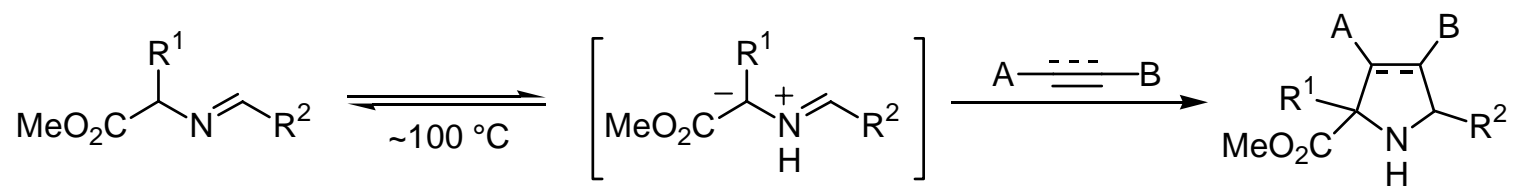

Azomethine imines are much less studied than azomethine ylides. One of the frequently employed methods for the generation of azomethine imines is a condensation of $N, N^{\prime}$ disubstituted hydrazines and aldehydes. ${ }^{13}$<smiles>C=CCCC(=O)NNCc1ccccc1</smiles><smiles>CC(C)[C@H](C=O)[C@H](C)CO</smiles><smiles>C=CCCC(=O)N(Cc1ccccc1)N=Cc1ccccc1</smiles><smiles>O=C1CCC2C[C@H](c3ccccc3)N(Cc3ccccc3)N12</smiles>

Hydrazones have been also used as azomethine imine precursors to achieve cycloadditions. ${ }^{14}$ The azomethine imines, generated by a formal 1,2-prototropic shift, undergo intermolecular cycloaddition with dipolarophiles to give pyrazolidine derivatives in low to moderate yields. 


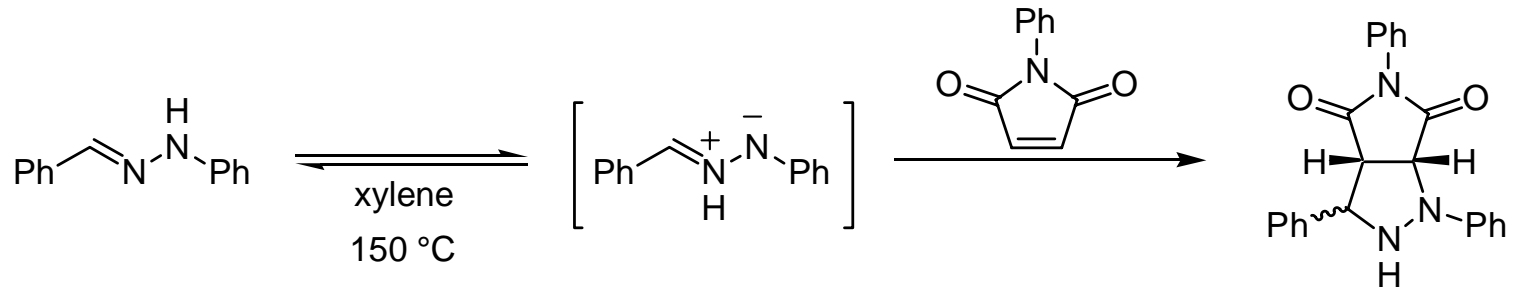

Alkylation of dialkyl- or arylalkylnitrosamines with alkylating agents give alkoxydiazenium salts in excellent yield. The salts are treated with base to give azomethine imines, which react with acetylenic dipolarophiles to give pyrazole derivatives. ${ }^{15}$ The azomethine imines also react with heteroaromatics such as pyridine, quinoline, isoquinoline, or phenanthridine.

As noted above, several methods for the generation of azomethine ylides and azomethine imines have been developed. However, in most cases, the substrates need special substituents and the reactions must be performed at high temperature or require multistep operations. These limitations reduce the synthetic utility of the reactions. From these reasons, we have created a potential strategy for generation of the 1,3-dipoles from $N$-silylmethylated imines and amides by the $1,2-{ }^{16}$ and 1,4-migration ${ }^{17}$ of silyl groups. Here, we will present effective generation and cycloaddition of azomethine ylides and azomethine imines utilizing 1,4-metallatropic strategy. Since the metallatropy are based on the strong affinity between silicon/tin and oxygen/sulfur, the method does not require any additives and bases for the generation of the dipoles, which can avoid limitations in the functional groups of starting materials and dipolarophiles in their cycloaddition. Moreover, the present method could realize the efficient generation of less- or non-stabilized 1,3-dipoles.

\section{Generation of Pyridinium Ylides from $N$-(Silylmethyl)pyridone Analogs via 1,4-Silatropy}

As mentioned in the introduction, we have already revealed thermal 1,4-silatropic generation of azomethine ylides from $N$-(silylmethyl)amides as shown in Scheme 1 and their cycloaddition with olefinic and acetylenic dipolarophiles leading to five-membered $N$-heterocycles. ${ }^{17}$ One of the characteristic advantages of our original procedure is that no additives or bases are required to generate azomethine ylides, which greatly expands the types of the starting materials and dipolarophiles applicable to the cycloaddition reactions. However, at the moment, 1,4-silatropy proceeds with difficulty when $\mathrm{R}^{3}$ is hydrogen; i.e. the generated 1,3-dipolar intermediates need an ylide-stabilizing group such as $\mathrm{Ph}$ or $\mathrm{Me}_{3} \mathrm{Si}$ on the a-carbon. 


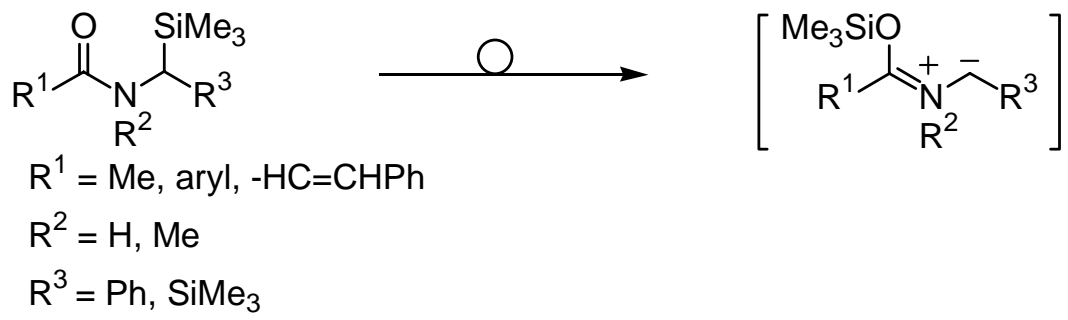

Scheme 1. Generation of azomethine ylides via 1,4-silatropy

If the methodology could be applied to $N$-(silylmethyl)pyridone analogs, where aromatization up to the silicon shift would be expected to become the driving force (Scheme 2), pyridinium ylides having no stabilizing group on the methylide carbon might be generated and their cycloaddition would give highly fused heterocycles. Although there are a number of reports of syntheses and reactions of pyridinium $N$-acylmethylides, ${ }^{18}$ only a few works have appeared on the chemistry of non-stabilized pyridinium $\mathrm{N}$-methylides; preparation by the deprotonation of $N$-methylpyridinium salts, ${ }^{19,20}$ the decarboxylation of pyridinium $N$-acetate ${ }^{6}$ or the desilylation of $N$-[(trimethylsilyl)methyl]pyridinium salt. ${ }^{21}$ From these points of view, we developed the novel generation of non-stabilized pyridinium ylides from $\mathrm{N}$ (silylmethyl)pyridone analogs via 1,4-silatropy and their cycloaddition, leading to multi-fused $N$ heterocycles.

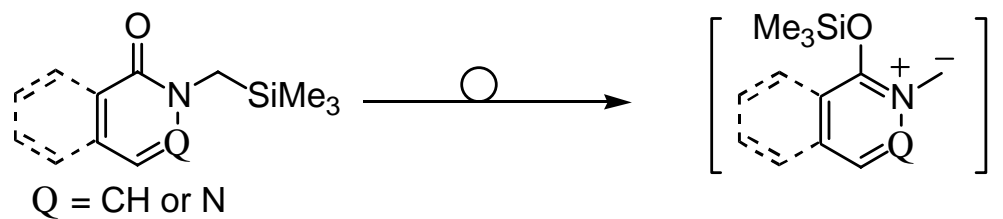

Scheme 2. Generation of non-stabilized azomethine ylides (pyridinium methylides) forced by aromatization through 1,4-silatropy

A solution of $N$-[(trimethylsilyl)methyl]pyridone (1a) and an equimolar amount of dimethyl acetylenedicarboxylate (DMAD) in toluene was refluxed for $30 \mathrm{~h}$ to give tetrahydroindolizinone derivative $\mathbf{2 a}$ in $30 \%$ yield along with indolizine $\mathbf{3} \mathbf{a}^{22}$ (5\%) and cyclazine $4 a(8 \%)$. 


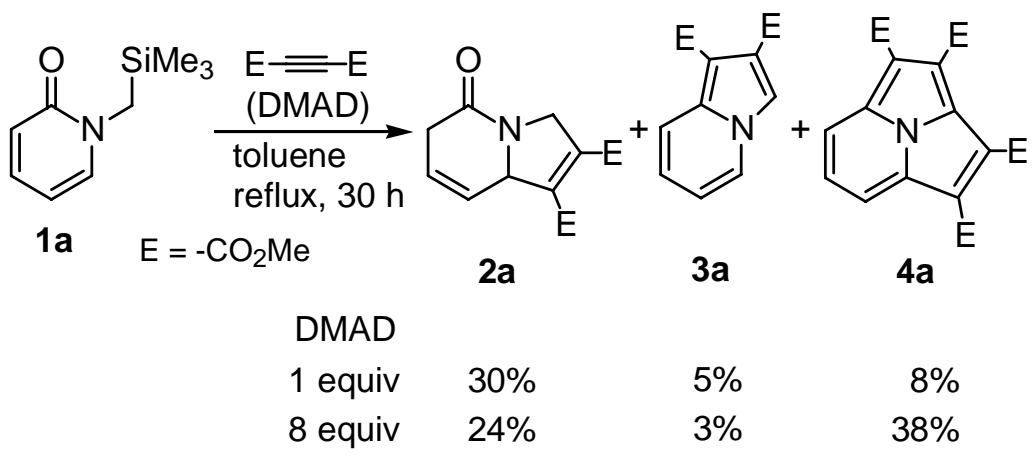

The cyclazine derivative 4a was obtained as the major product (38\% yield) by increasing the amount of DMAD (8 equiv) used in the reaction. These results are summarized in equation (1).

The formation of cycloadducts 2a, 3a and $\mathbf{4 a}$ can be explained as follows. Initially, the rearrangement of the silyl group of 1a onto the oxygen via a five-membered ring transition state gives rise to non-stabilized pyridinium methylide 5a, where aromatization of the pyridone ring of 1a by 1,4-silatropy would constitute the driving force for the reaction. The ylide undergoes 1,3dipolar cycloaddition with DMAD to afford two types of regioisomers, followed by hydrolysis of $\mathbf{6 a}$ and the elimination of silanol from 7a to yield $\mathbf{2 a}$ and 3a, respectively. It has been previously shown that the cycloaddition of $\mathbf{3 a}$ with DMAD gives cyclazine $\mathbf{4 a}$ with the evolution of hydrogen. ${ }^{23}$

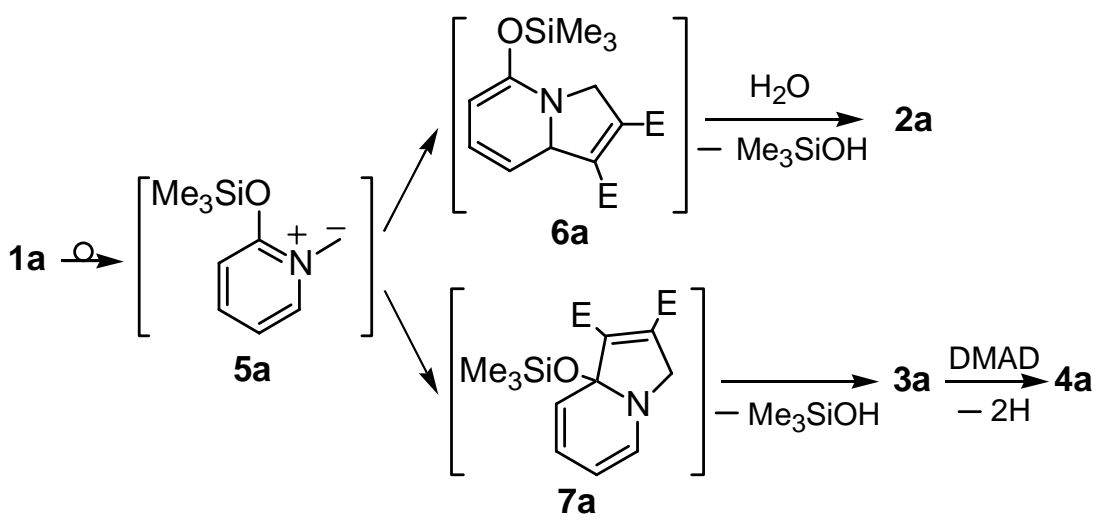

Scheme 3. Plausible reaction pathways

The present reaction was successfully applied to the synthesis of heterotricycles from $N$ silylmethylated bicyclic amides as listed in Table 1 . When $N$-(silylmethyl)isoquinoline $\mathbf{1 b}$ was treated with DMAD at $180{ }^{\circ} \mathrm{C}$ for $6 \mathrm{~h}$, pyrroloquinoline derivative $3 \mathbf{b}$ was produced as the sole cycloadduct in $69 \%$ yield. Thus the cycloaddition was completely regioselective in clear contrast to that of pyridone 1a. The employment of isoquinoline 1c to which a phenyl substituent is attached to the silyl group permitted the reaction temperature to be lowered $\left(80{ }^{\circ} \mathrm{C}\right)$ to give the 
desired product efficiently. Although it took $48 \mathrm{~h}$ to complete the cycloaddition of $\mathrm{N}$ [(trimethylsilyl)methyl]phthalazone (1d) with DMAD at $200{ }^{\circ} \mathrm{C}$, the introduction of phenyl group on the silicon, which is the migrating unit, reduced the reaction time by half at the same temperature. Quinolone and quinoxalone derivatives $1 \mathbf{f}$ and $\mathbf{1 g}$ were also converted into the corresponding heterocycles in high yields by reactions with DMAD. When an unsymmetrical dipolarophile, ethyl propiolate, was employed in the reaction of quinoxalone 1g, the cycloaddition proceeded regioselectively to give $\mathbf{8 g}$ in $59 \%$ yield. The present reaction was found to be applicable to olefinic dipolarophiles such as dimethyl fumarate and acrylonitrile, leading to unsaturated heterotricycles $\mathbf{9 g}$ and $\mathbf{1 0 g}$ in the cycloaddition with $\mathbf{1 g}$.

Table 1. Synthesis of heterocycles from $N$-silylmethylated bicyclic amides via 1,4-silatropy

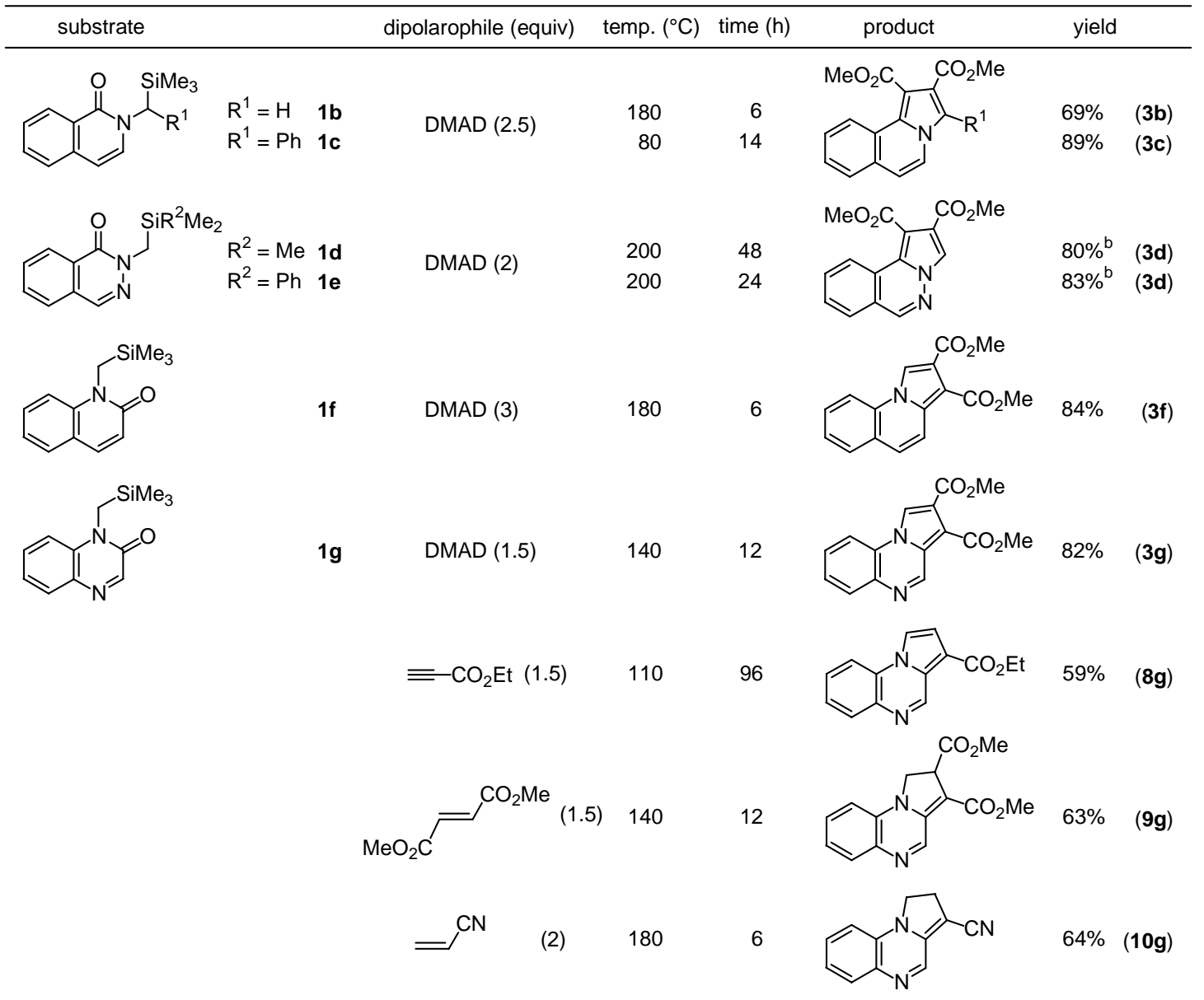

${ }^{\mathrm{a}}$ Reaction conditions: in benzene or $d_{6}$-benzene, sealed in a glass tube. ${ }^{\mathrm{b}}$ Determined by ${ }^{1} \mathrm{H}-\mathrm{NMR}$.

As described above, the novel generation of non-stabilized pyridinium ylides from $N$ (silylmethyl)pyridone analogs via 1,4-silatropy and their cycloaddition lead to fused $\mathrm{N}$ heterocycles. In the present cycloaddition series, the aromatization of 6-membered heterocycles 
would be predicted to be the driving force, not only for the generation of non-stabilized ylides but also the induction of 1,4-silatropy.

\section{Generation of Azomethine Ylides as Nitrile Ylide Equivalents from $N$ - (Stannylmethyl)thioamides via 1,4-Stannatropy}

The azomethine ylides generated by our method are regarded as nitrile ylide equivalents, because adducts of the corresponding nitrile ylides were obtained as the result of cycloaddition of the azomethine ylides followed by the elimination of silanol.

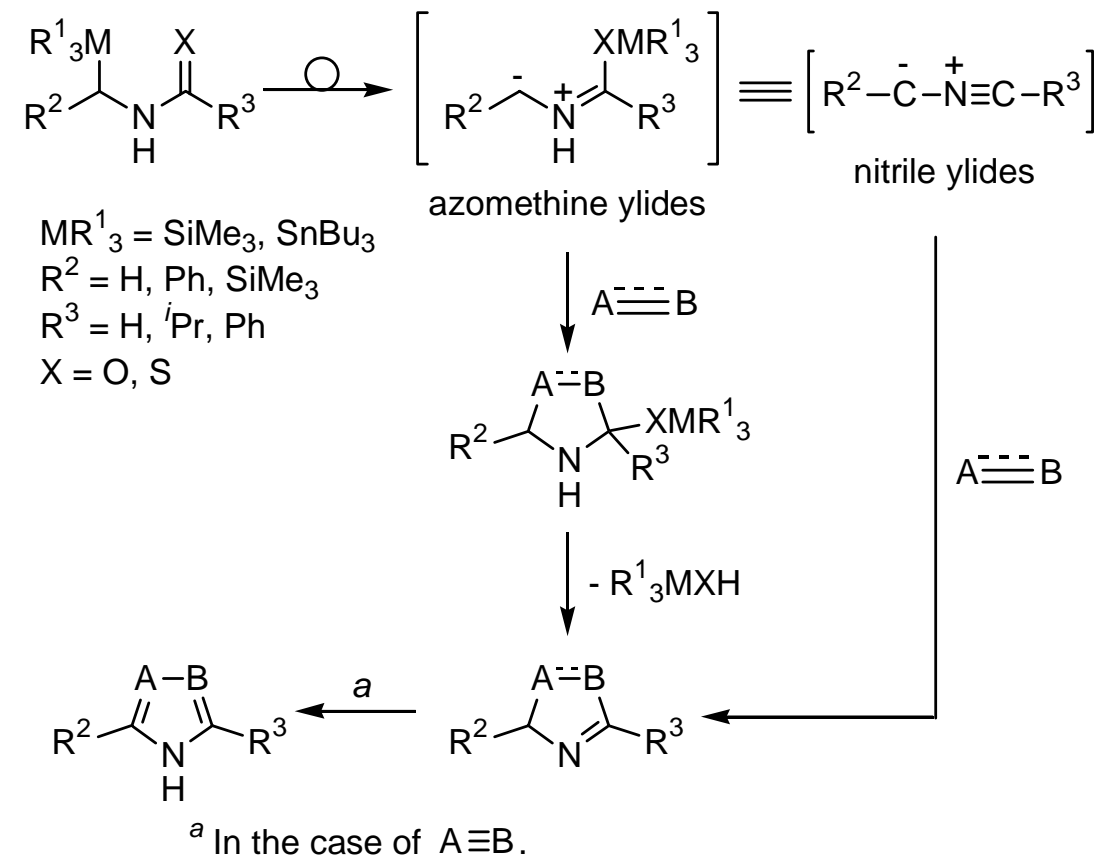

Scheme 4. Generation of azomethine ylides via 1,4-metallatropy

Stabilized azomethine ylides having aryl or electron-withdrawing groups at 1- or 3positions are generated under moderate reaction temperature. However, when precursors of lessor non-stabilized azomethine ylides were employed, a high reaction temperature was required to generate the ylide intermediates. While generation of stabilized azomethine ylides under mild conditions is comparatively easy, generation of less- and non-stabilized azomethine ylides is a significant challenge in this field. Since it is well known that a sulfur atom stabilizes an adjacent ion and $\mathrm{C}=\mathrm{S}$ bonds of thioamides are extensively polarized compared to $\mathrm{C}=\mathrm{O}$ bonds of amides, $\alpha$-metallothioamides would be expected to be better candidates for 1,4-sila- and/or stannatropy leading to less or non-stabilized azomethine ylides. Moreover, a tin atom has stronger affinity for a sulfur atom than a silicon atom, suggesting that $N$-(stannylmethyl)thioamides might be better starting materials. $^{24}$ In this section, the highly effective cycloaddition of azomethine 
ylides generated by 1,4-stannatropy of $N$-(stannylmethyl)thioamides under neutral conditions is described. Although a number of studies of $1,2-{ }^{25}$ and 1,3 -stannatropy ${ }^{26}$ have been reported, there is just one example of an anionic reaction via 1,4-stannatropy, ${ }^{27}$ and, hence, this type of migration under neutral condition is unprecedented to the best of our knowledge. ${ }^{28}$

The cycloaddition of azomethine ylides generated from $\alpha$-metalloamides with dimethyl fumarate (12a) is shown in Table 2. The reaction of $N$-(silylmethyl)amide 11a with the fumarate in benzene at $200{ }^{\circ} \mathrm{C}$ for $30 \mathrm{~h}$ afforded cycloadduct 13a in very low yield. In clear contrast to the silylmethylamide, the reaction of $N$-(silylmethyl)thioamide $\mathbf{1 1 b}$ proceeded much more smoothly to give the same product. Surprisingly, the reaction of $N$-(stannylmethyl)thioamide 11c was complete within $3 \mathrm{~h}$ even at $60{ }^{\circ} \mathrm{C}$ giving the cycloadduct 13a in high yield. Thus $N$ (stannylmethyl)thioamide 11c is the best precursor for the generation of the azomethine ylide. Since the reaction of amides $\mathbf{1 1}$ with alkenes and an alkyne gave the cooresponding pyrrolines and pyrrole, the azomethine ylides generated from amides $\mathbf{1 1}$ are nitrile ylide equivalents most of which are difficult to be generated by conventional methods. ${ }^{28 c, 29}$

Table 2. Cycloaddition of azomethine ylides generated by 1,4-metallatropy

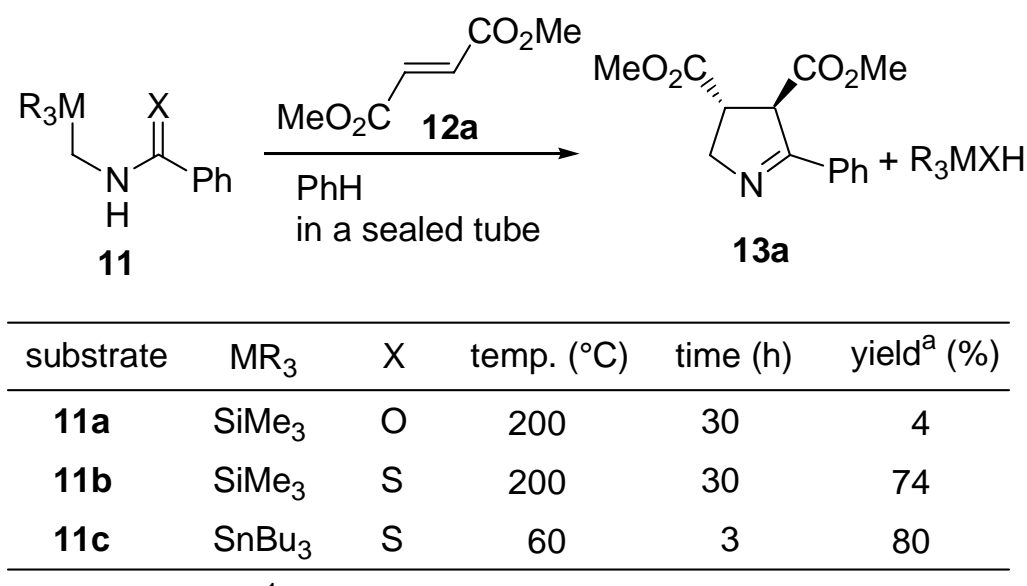

${ }^{\text {a }}$ Determined by ${ }^{1} \mathrm{H}-\mathrm{NMR}$.

The reactions of $N$-stannylthioamide $\mathbf{1 1}$ with various dipolarophiles are shown in Table 3. The reaction with dimethyl maleate (12b) gave cycloadduct 13a which is the same product obtained in the reaction with dimethyl fumarate (12a) (entry 1). The result can be explained by isomerization at the 3-position of the initial 3,4-cis adduct because of the high acidity of the hydrogen at the 3-position and the stability of the 3,4-trans structure. When fumaronitrile (12c) was employed, 2-pyrroline derivative 14a was obtained probably because of smaller steric repulsion between the substituents at the 3- and 4-positions in cycloadduct 14a compared to cycloadduct 13a (entry 2). The reaction with $N$-phenylmaleimide (12d), a cyclic dipolarophile, afforded cycloadduct $\mathbf{1 3 b}$ in high yield (entry 3 ). 
Table 3. Cycloaddition of azomethine ylides generated from $N$ (tributylstannylmethyl)thiobenzamides 11c,d

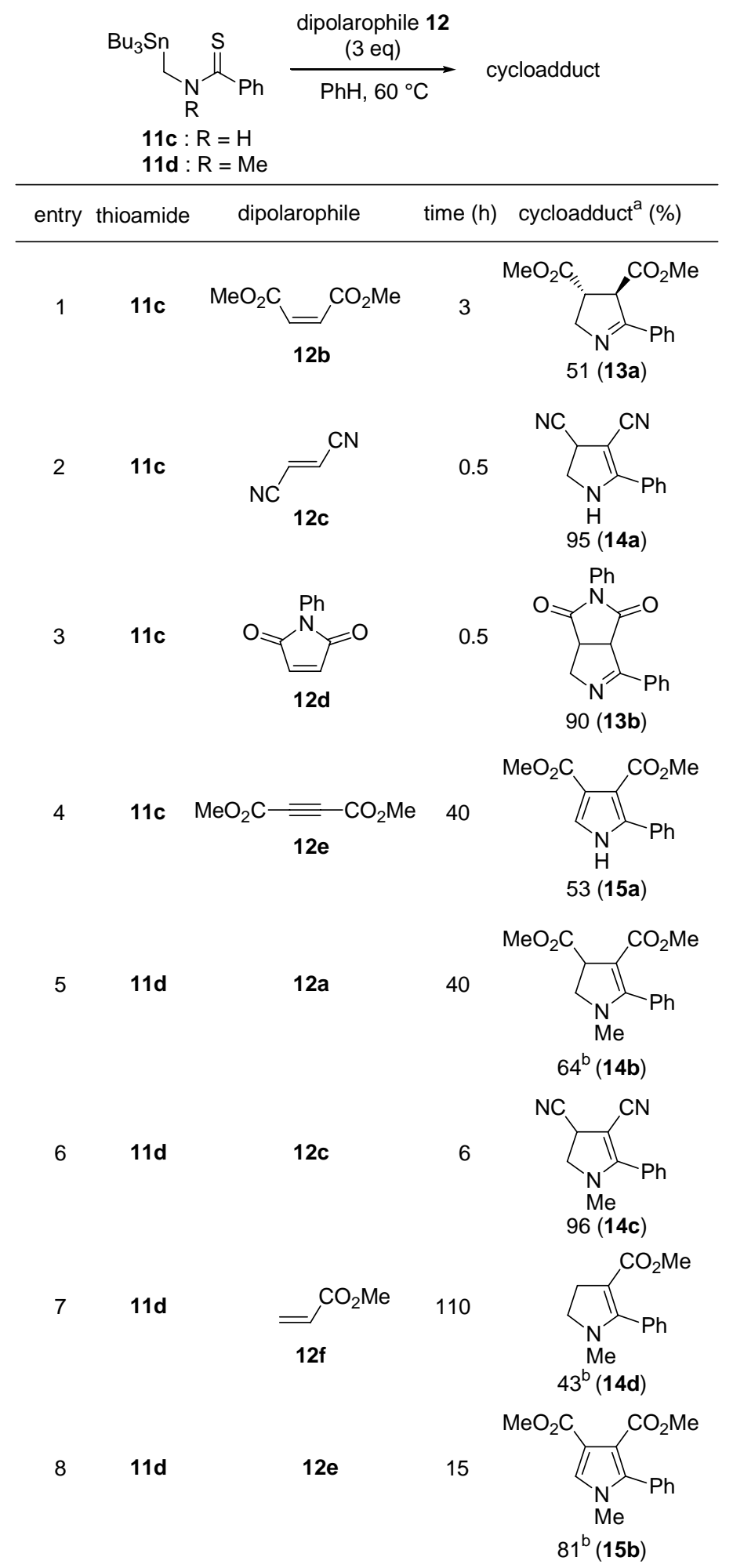

${ }^{\mathrm{a}}$ Determined by ${ }^{1} \mathrm{H}-\mathrm{NMR} .{ }^{\mathrm{b}}$ isolated yields. 
In the case where dimethyl acetylenedicarboxylate (DMAD, 12e), an electron-deficient alkyne, was used, pyrrole derivative 15a was obtained (entry 4). Analogously, the reactions of $\mathrm{N}$ methyl- $N$-(stannylmethyl)thioamide 11d with dipolarophiles, electron-deficient alkenes and an alkyne, gave the corresponding cycloadducts in good yields under very mild conditions (entries 5-8). Among these, it is noteworthy that cycloadduct 14d obtained from the reaction with methyl acrylate (12f), an unsymmetrical dipolarophile, was produced with complete regioselectivity.

Surprisingly, the cycloaddition of azomethine ylides having destabilizing substituents or no substituents could also be carried out (Table 4).

The introduction of an alkyl group to the 1- or 3-position of 1,3-dipoles causes extensive destabilization of the 1,3-dipoles. However, when $N$-(stannylmethyl)thioisobutyramide 11e was employed in the reactions with dimethyl fumarate (12a) and fumaronitrile (12c), the corresponding cycloadducts $\mathbf{1 3} \mathbf{c}$ and $\mathbf{1 4} \mathbf{e}$ were readily obtained (entries 1 and 2). The reactions of $\mathrm{N}$-(stannylmethyl)thioformamide $\mathbf{1 1 f}$ and $\mathrm{N}$-methyl- $\mathrm{N}$-(stannylmethyl)thioformamide $\mathbf{1 1 g}$ with these dipolarophiles afforded 2,5-unsubstituted pyrrolines 13d, 14f, 14g, and 14h in good yields respectively (entries 3-6). It is noteworthy that the azomethine ylide generated from thioamide $\mathbf{1 1 f}$ is an ultimately non-substituted nitrile ylide equivalent, and thus, it is a very useful reactive species for the synthesis of less-substituted N-containing 5-membered heterocycles. When DMAD was employed, the reaction proceeded at ambient temperature to give pyrrole derivative 15c in high yield (entry 7). The 2,5-unsubstituted pyrrolines and pyrroles are known, for example, to be precursors of polypyrroles which are mainly useful for conducting polymers.

As mentioned in this section, we demonstrated an unprecedented method of effective generation of azomethine ylides on the basis of a new strategy using 1,4-stannatropy. Cycloaddition of the azomethine ylides, or nitrile ylide equivalents, proceeded under mild conditions to give pyrroline and pyrrole derivatives in good to excellent yields. 
Table 4. Cycloaddition of azomethine ylides generated from $N$ (tributylstannylmethyl)thiobenzamides 11e-g

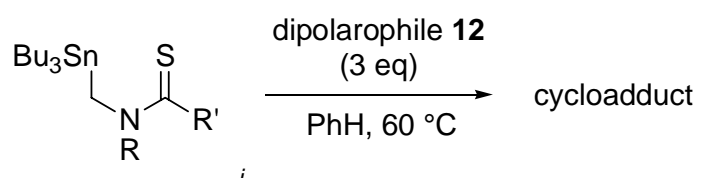

11e : $\mathrm{R}=\mathrm{H}, \mathrm{R}^{\prime}={ }^{i} \mathrm{Pr}$

11f : $R=H, R^{\prime}=H$

$11 \mathrm{~g}: \mathrm{R}=\mathrm{Me}, \mathrm{R}^{\prime}=\mathrm{H}$

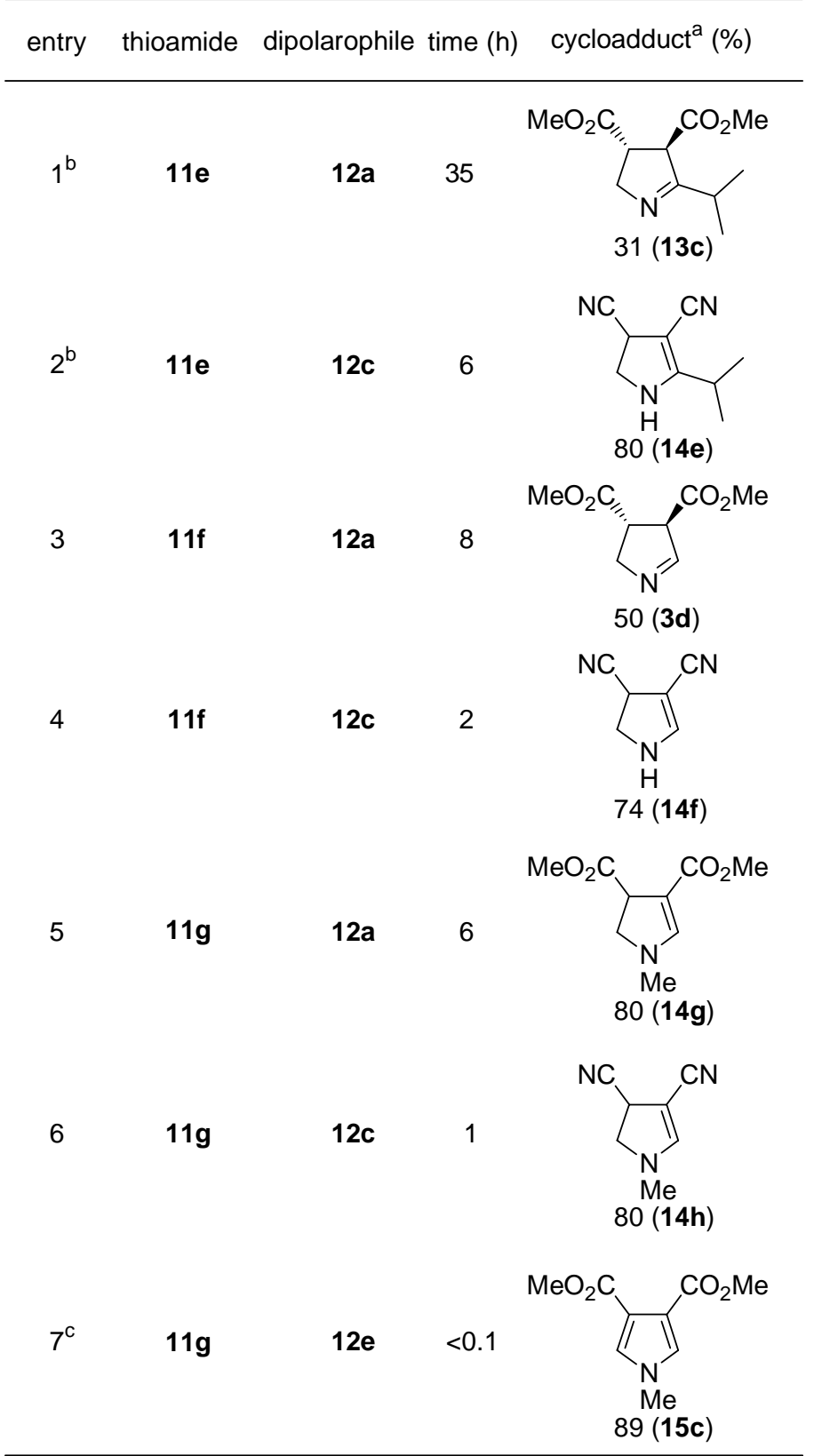

${ }^{\mathrm{a}}$ Isolated yields. ${ }^{\mathrm{b}}$ Reaction temperature: $100{ }^{\circ} \mathrm{C}$. ${ }^{\mathrm{c}}$ Reaction temperature: $20^{\circ} \mathrm{C}$. 


\section{Generation of Azomethine Imines from $\alpha$-Silylnitrosamines via 1,4- Silatropy and Their Cycloaddition}

Azomethine imines ${ }^{30}$ are important intermediates for the synthesis of various pyrazole, pyrazoline, and pyrazolidine derivatives. In spite of their significance, there are few established methods for the generation. As mentioned in the introductory part, the typical procedures reported so far are a thermal 1,2-hydrogen shift of hydrazone derivatives ${ }^{31}$ and a condensation of aldehydes with $N, N$ '-disubstituted hydrazines. ${ }^{32}$ Alternatively, treatment of $N$-nitrosamine derivatives with alkylating agents or organometallic reagents followed by deprotonation of the hydrogen on the $\alpha$-carbon also gives azomethine imines. However, in most cases, the generation and subsequent cycloaddition of the azomethine imines must be performed under reflux in highboiling solvents with long reaction times or they require multistep operations. Therefore, it appeared to the author that there exists the need for development of a novel method which can be performed under mild conditions.

The efficient generation of azomethine ylides from $N$-(silylmethyl)imines ${ }^{16}$ or $N$ (silylmethyl)amides ${ }^{17}$ via an intramolecular silatropic shift, whose methodologies have been developed by our group, is based on the strong affinity between silicon and oxygen or nitrogen. In connection with this, $N$-nitrosamines are close analogues of tertiary amides and a lone pair of electrons on the amino nitrogen is delocalized into the $\pi$-electron system of the $\mathrm{N}=\mathrm{O}$ bond to a greater extent than in the case of amides. ${ }^{34}$ Thus, dipole moments of $N$-nitrosamines are significantly larger than those of tertiary amides, and, as a result, should indicate a larger affinity of the nitroso oxygen atom towards a silicon atom. ${ }^{34}$ With these facts in mind, it may be expected that $\alpha$-silylnitrosamines could be excellent precursors of azomethine imines (Scheme 5).
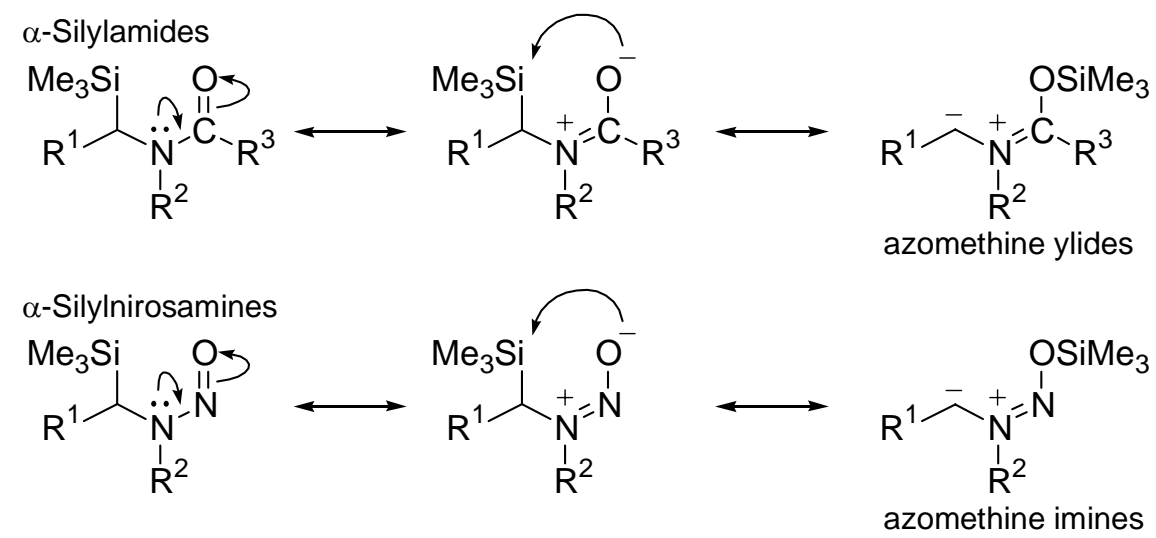

Scheme 5. Comparison of resonance structures of $\alpha$-silylamides

For example, $N$-methyl- $N$-nitroso- $\alpha$-(trimethylsilyl)benzylamine (16a) was treated with 1 equiv of dimethyl acetylenedicarboxylate (DMAD) in refluxing toluene for $1 \mathrm{~h}$ to give 3,4dimethoxycarbonyl-1-methyl-5-phenylpyrazole (17) in 83\% yield (eq 2). The product was 
isolated by silica gel chromatography and the structure was determined by spectral analysis. The role of the silyl group is very important, as evidenced by the fact that $N$-methyl- $N$ nitrosobenzylamine (18), which lacks a silyl group, did not give any cycloadduct with DMAD in refluxing toluene for $10 \mathrm{~h}$ (eq 3).

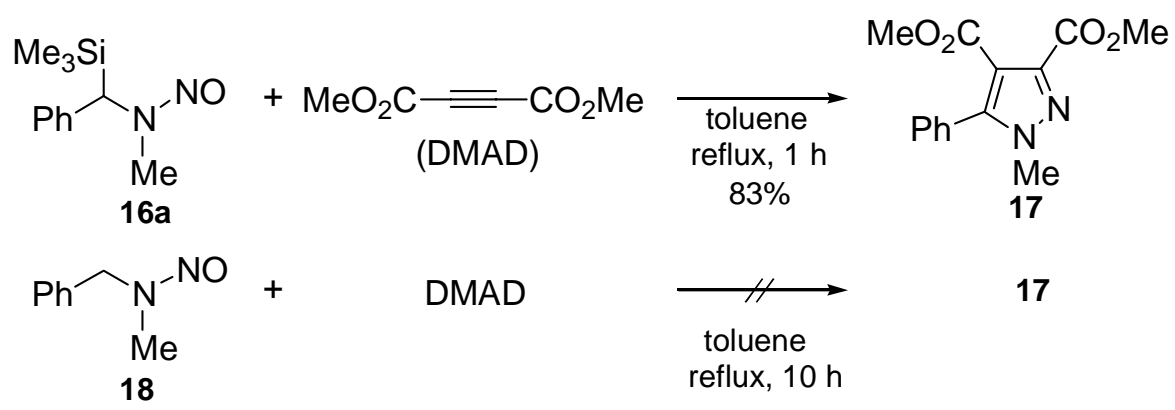

Scheme 6 shows a plausible mechanism which accounts for the formation of the azomethine imine $\mathbf{A}$ and the subsequent cycloaddition. A thermal 1,4-shift of the silyl group onto the oxygen of nitroso group gives the azomethine imine intermediate (A) which undergoes 1,3-dipolar cycloaddition with DMAD to give the 5-membered ring adduct $(\mathbf{B})$. Elimination of a silanol from $\mathbf{B}$ affords the aromatized product, pyrazole 17.

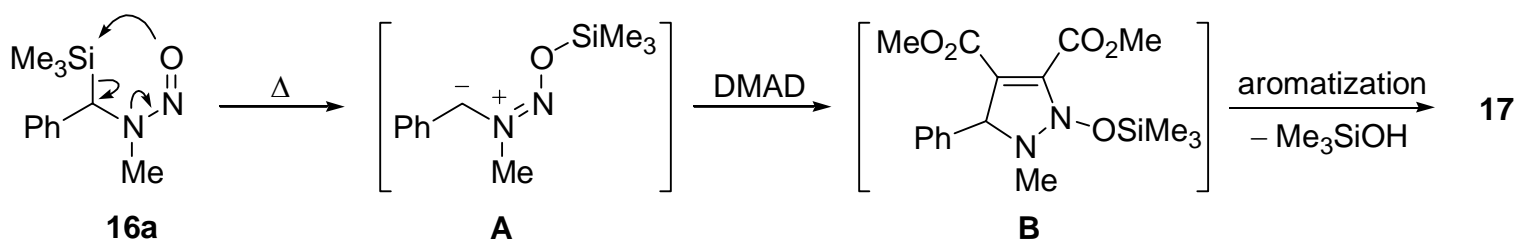

Scheme 6. Generation of an azomethine imine by 1,4-silatropy and its cycloaddition

To assess the reaction efficiency, we examined the effect of temperature on the reaction of 16a with DMAD (Table 5). The reaction was rather sluggish at room temperature and 17 was obtained in $30 \%$ yield after $7 \mathrm{~d}$, with ca. $50 \%$ of the starting 16 a remaining (entry 1 ). The reaction was accelerated by heating and was essentially complete after $12 \mathrm{~h}$ at $50{ }^{\circ} \mathrm{C}$ or $1 \mathrm{~h}$ at $80{ }^{\circ} \mathrm{C}$ (entries 2 and 3). Furthermore, it is noteworthy that at $110^{\circ} \mathrm{C}$, the reaction was complete within 5 min, giving a quantitative yield of 17 (entry 4). To gain additional insights into the reaction mechanism, the rates of formation of 17 at $80{ }^{\circ} \mathrm{C}$ under several concentrations of substrates were compared. For all concentrations, the reaction rates were nearly the same, indicating that the formation of the azomethine imine involves an intramolecular silatropic shift and is the rate-limiting step. 
Table 5. Effect of temperature on the reaction of $16 \mathbf{a}$ with $\mathrm{DMAD}^{\mathrm{a}}$

\begin{tabular}{cccc}
\hline entry & temp. $\left({ }^{\circ} \mathrm{C}\right)$ & time $(\mathrm{h})$ & yield of $\mathbf{1 7}(\%)^{\mathrm{b}}$ \\
\hline 1 & 25 & 168 & 30 \\
2 & 50 & 12 & 82 \\
3 & 80 & 1 & 98 \\
4 & 110 & 0.05 & 100 \\
\hline
\end{tabular}

${ }^{\mathrm{a}}$ Reactions were carried out under $\mathrm{N}_{2}$ with 16a $(0.05 \mathrm{mmol})$, DMAD (0.05 mmol) in $\mathrm{C}_{6} \mathrm{D}_{6}$ in a sealed NMR tube. ${ }^{\mathrm{b}}$ determined by ${ }^{1} \mathrm{H}-\mathrm{NMR}$ analysis.

In Table 6 are listed the results of the cycloadditions of $\alpha$-silylnitrosamines (16a-e) with several dipolarophiles. When 16a was reacted with a monosubstituted dipolarophile such as ethyl propiolate, a mixture of 3- and 4-substituted pyrazoles was obtained in good yield (entry 1). These pyrazoles were readily separable by silica gel chromatography and the ratio of 3- and 4substituted pyrazoles was found to be 85 : 15 . Both substrates bearing electron-donating (4methoxy, 16b) and electron-withdrawing (4-fluoro, 16c) substituents at the phenyl group reacted smoothly with DMAD to afford the desired pyrazoles in excellent yields (entries 2 and 3). Thus, it appears likely that the substituents at the 4-position of the phenyl group had no effect on the high reactivity of the $\alpha$-silylnitrosamines. 3-Thienyl substituted substrate $\mathbf{1 6 d}$ also reacted with DMAD under the same conditions to give nearly quantitative yield of pyrazole 23 (entry 4). We next examined whether or not the less-stabilized azomethine imines, which possess no ylidestabilizing substituents on the carbon, can be generated. Thus 16e was treated with 1 equiv of DMAD in refluxing toluene for $1 \mathrm{~h}$ to give pyrazole 24 in 84\% yield, suggesting that this reaction proceeds via a less-stabilized azomethine imine intermediate (entry 5).

The results of extensive experiments with other dipolarophiles are also summarized (entries 6-9). The reaction with ethyl propiolate gave regioselectively one product, the 3substituted pyrazole 25 (entry 6). However, with an unsymmetrically disubstituted dipolarophile such as methyl phenylpropiolate, a mixture of $\mathbf{2 6}$ and $\mathbf{2 7}$ was obtained with no selectivity (entry 7). The reaction with phenylacetylene also proceeded to give only the 3-substituted pyrazole 28 albeit in a low yield (entry 8). Diphenylacetylene showed no reactivity toward 16e (entry 9). The observed order of reactivity of these acetylenes is in good agreement with those of the cycloadditions of well-known 1,3-dipoles with dipolarophiles. ${ }^{35}$ 
Table 6. Cycloaddition reactions of $\alpha$-silylnitrosamines with dipolarophiles ${ }^{\mathrm{a}}$

entry

${ }^{\mathrm{a}}$ All reactions were carried out in refluxing toluene for $1 \mathrm{~h}$ with 1 equiv. of the dipolarophile. bIsolated yields.

All the reactions described above gave $N$-substituted pyrazole derivatives, since the readily available substrates $\mathbf{1 6}$ are secondary nitrosamines. For the synthesis of $N$-unsubstituted pyrazole derivatives, $\alpha$-silylnitrosoamide was chosen as a precursor of the 1,3-dipole. A similar 1,4-silatropic shift would generate $N$-acylazomethine imines which react with dipolarophiles to afford $N$-acylpyrazole derivatives, whose acyl group is expected to be a potent leaving group as, for example, acyl pyrazoles are readily hydrolyzed to $N$-unsubstituted pyrazoles. ${ }^{36}$ Indeed, this 
strategy was so successful that $N$-unsubstituted pyrazole derivatives were obtained without any treatment after cycloaddition. For example, $\alpha$-silylnitrosoamide 29 was reacted with 1 equiv of DMAD in toluene at $80{ }^{\circ} \mathrm{C}$ for $1 \mathrm{~h}$ to give $N$-unsubstituted pyrazole 30 in $96 \%$ yield (eq 4).

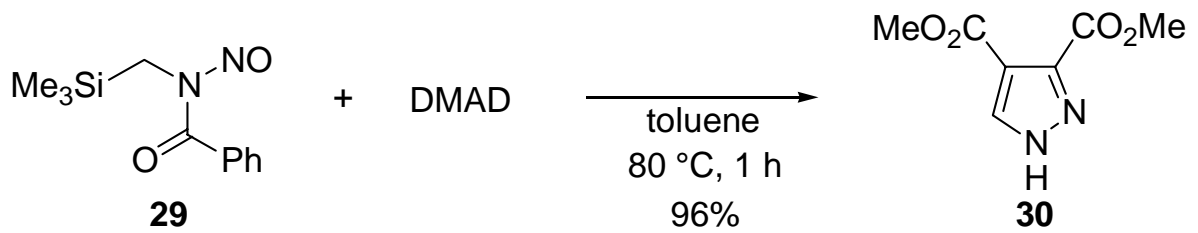

\section{Conclusions}

The present studies are concerned with the novel methods for generation of azomethine ylides and azomethine imines. This series of works provide novel methodologies for the synthesis of a variety of five-membered nitrogen-containing heterocycles including heteropolycycles, which are useful as frameworks or side-chains of drugs, agricultural chemicals, functional materials, and so on. The methodologies for generation of the 1,3-dipoles are based on the strong affinity of silicon/tin and oxygen/sulfur atoms. One of the useful features of the methods is that the dipoles can be generated under completely neutral conditions in the absence of additives. Moreover, less- or non-stabilized dipoles, which are very difficult to generate, are successfully created by the strategy providing the general procedure for synthesis of a variety of heterocycles.

\section{References}

1. See, for example: Katritzky, A. R., Rees, C. W., Scriven, E. F. V., Eds. Comprehensive Heterocyclic Chemistry II; Elsevier: Oxford, 1996; Vols. 1-9.

2. Huisgen, R. In 1,3-Dipolar Cycloaddition Chemistry; Padwa, A., Ed.; John Wiley \& Sons: New York, 1984; Vol. 1, p 1.

3. For reviews, see: (a) Lown, J. W. In 1,3-Dipolar Cycloaddition Chemistry; Padwa, A., Ed.; John Wiley \& Sons: New York, 1984; Vol. 1, p 653. (b) Vedejs, E.; West, F. G. Chem. Rev. 1986, 86, 941. (c) Tsuge, O.; Kanemasa, S. In Advances in Heterocyclic Chemistry; Katritzky, A. R., Ed.; Academic Press: San Diego, 1989; Vol. 45, p 231.

4. For a review, see: Grashey, R. In 1,3-Dipolar Cycloaddition Chemistry; Padwa, A. Ed.; John Wiley \& Sons: New York, 1984; Vol. 1, p 733.

5. Huisgen, R. J. Org. Chem. 1976, 41, 403.

6. (a) Heine, H. W.; Peavy, R. E. Tetrahedron Lett. 1965, 3123. (b) Padwa, A.; Hamilton, L. Tetrahedron Lett. 1965, 4363. (c) Huisgen, R.; Scheer, W.; Huber, H. J. Am. Chem. Soc. 1967, 89, 1753. (d) Woller, P. B.; Cromwell, N. H. J. Org. Chem. 1970, 35, 888. (e) Lown, J. W. Rec. Chem. Prog. 1971, 32, 51. (f) Kellogg, R. M. Tetrahedron 1976, 32, 2165. 
7. (a) Vedejs, E.; Martinez, G. R. J. Am. Chem. Soc. 1979, 101, 6452. (b) Vedejs, E.; Martinez, G. R. J. Am. Chem. Soc. 1980, 102, 7993. (c) Vedejs, E.; West, F. G. J. Org. Chem. 1983, 48, 4773. (d) Padwa, A.; Haffmanns, G.; Tomas, M. J. Org. Chem. 1984, 49, 3314. (e) Vedejs, E.; Larsen, S.; West, F. G. J. Org. Chem. 1985, 50, 2170. (f) Tsuge, O.; Kanemasa, S.; Matsuda, K. Chem. Lett. 1985, 1411. (g) Tsuge, O.; Kanemasa, S.; Matsuda, K. J. Org. Chem. 1986, 51, 1997. (h) Tsuge, O.; Hatta, T.; Kakura, Y.; Tashiro, H.; Maeda, H.; Kakehi, A. Chem. Lett. 1997, 945.

8. (a) Achiwa, K.; Sekiya, M. Chem. Lett. 1981, 1213. (b) Smith, R.; Livinghouse, T. J. Org. Chem. 1983, 48, 1554. (c) Livinghouse, T.; Smith, R. J. Chem. Soc., Chem. Commun. 1983, 210.

9. (a) Achiwa, K.; Sekiya, M. Tetrahedron Lett. 1982, 23, 2589. (b) Imai, N.; Terao, Y.; Achiwa, K. Heterocycles 1985, 23, 1107.

10. Achiwa, K.; Imai, N.; Motoyama, T.; Sekiya, M. Chem. Lett. 1984, 2041.

11. (a) Tsuge, O.; Kanemasa, S.; Hatada, A.; Matsuda, K. Chem. Lett. 1984, 801. (b) Tsuge, O.; Kanemasa, S.; Yamada, T.; Matsuda, K. Heterocycles, 1985, 23, 2489. (c) Tsuge, O.; Kanemasa, S.; Hatada, A.; Matsuda, K. Bull. Chem. Soc. Jpn., 1986, 59, 2537. (d) Tsuge, O.; Kanemasa, S.; Yamada, T.; Matsuda, K. J. Org. Chem. 1987, 52, 2523.

12. (a) Grigg, R.; Kemp, J. J. Chem. Soc. Chem. Commun., 1977, 125. (b) Grigg, R.; Kemp, J. J. Chem. Soc., Chem. Commun., 1978, 109. (c) Yamada, S.; Hongo, C.; Yoshioka, R.; Chibata, I. J. Org. Chem. 1983, 48, 843. (d) Grigg, R.; Gunaratne, H. Q. N. Tetrahedron Lett. 1983, 24, 4457.

13. Oppolzer, W. Tetrahedron Lett. 1972, 17, 1707.

14. (a) Arrieta, A.; Carrillo, J. R.; Cossío, F. P.; Díaz-Oritz, A.; Gómez-Escalonilla, M. J.; De la Hoz, A.; Langa, F.; Moreno, A. Tetrahedron 1998, 54, 13167. (b) Sun, B.; Adachi, K.; Noguchi, M. Synthesis 1997, 53. (c) Sun, B.; Adachi, K.; Noguchi, M. Tetrahedron 1996, 52, 901. (d) Noguchi, M.; Yamada, K. Synthesis 1993, 145. (e) Noguchi, M.; Kiriki, Y.; Tsuruoka, T.; Mizui, T.; Kajigaeshi, S. Bull. Chem. Soc. Jpn. 1991, 64, 99. (f) Kanemasa, S.; Tomoshige, N.; Wada, E.; Tsuge, O. Bull. Chem. Soc. Jpn. 1989, 62, 3944. (g) Grigg, R.; Dowling, M.; Jordan, M. W.; Sridharan, V.; Thianpatanagul, S. Tetrahedron 1987, 43, 5873. (h) LeFevre, G.; Hamelin, J. Tetrahedron Lett. 1978, 19, 4503. (i) Grigg, R.; Kemp, J.; Thompson, N. Tetrahedron Lett. 1978, 19, 2827.

15. (a) Farina, P. R.; Tieckelmann, H. J. Org. Chem. 1975, 40, 1070.(b) Eicher, T.; Hünig, S.; Nikolaus, P. Chem. Ber. 1969, 102, 3176. (c) Eicher, T.; Hünig, S.; Hansen, H.; Nikolaus, P. Chem. Ber. 1969, 102, 3159. (d) Eicher, T.; Hünig, S.; Hansen, H. Chem. Ber. 1969, 102, 2889.

16. (a) Komatsu, M.; Okada, H.; Yokoi, H.; Minakata, S. Tetrahedron Lett. 2003, 44, 1603. (b) Okada, H.; Akaki, T.; Oderaotoshi, Y.; Minakata, S.; Komatsu, M. Tetrahedron 2003, 59, 197. (d) Komatsu, M.; Okada, H.; Akaki, T.; Oderaotoshi, Y.; Minakata, S. Org. Lett. 2002, 4, 3505. 
17. (a) Ohno, M.; Komatsu, M.; Miyata, H.; Ohshiro, Y. Tetrahedron Lett. 1991, 32, 5813. (b) Komatsu, M.; Ohno, M.; Tsuno, S.; Ohshiro, Y.; Chem. Lett. 1990, 19, 575. (c) Iyoda, M.; Sultana, F.; Kato, A.; Yoshida, M.; Kuwatani, Y.; Komatsu, M.; Nagase, S. Chem. Lett. 1995, 24, 1133.

18. (a) Uchida, T.; Matsumoto, K. Synthesis 1976, 209. (b) Swinbourne, F. J.; Hunt, J. H.; Klinkert, G. In Advances in Heterocyclic Chemistry, Vol. 23; Katritzky, A. R.; Boulton, A. J. Eds.; Academic Press: New York, 1978, 103.

19. Kröhnke, F. Angew. Chem. 1953, 65, 605.

20. Ratts, K. W.; Howe, R. K.; Phillips, W. G. J. Am. Chem. Soc. 1963, 91, 6115.

21. (a) Tsuge, O.; Kanemasa, S.; Kuraoka, S.; Takenaka, S. Chem. Lett. 1984, 279. (b) Miki, Y.; Hachiken, H.; Takemura, S. Heterocycles 1984, 22, 701.

22. Sliwa, W. Heterocycles 1984, 22, 705.

23. Matsuda, Y.; Kohra, S.; Katou, K.; Itou, T.; Uemura, T. Heterocycles 1997, 45, 2223.

24. (a) Tzschach, A.; Jurkschat, K. Pure Appl. Chem. 1986, 58, 639. (b) Itoh, K.; Fukumoto, Y.; Ishii, Y. Tetrahedron Lett. 1968, 9, 3199. (c) Reiche, W. T. Inorg. Chem. 1962, 1, 650. (d) Bloodworth, A. J.; Davis, A. G.; Vasishtha, S. C. J. Chem. Soc. (C) 1967, 1309.

25. (a) Dussault, P. H.; Zope, U. R. Tetrahedron Lett. 1995, 36, 2187. (b) Iwamoto, K.; Chatani, N.; Murai, S. J. Organomet. Chem. 1999, 574, 171.

26. (a) Pereyre, M.; Bellegarde, B.; Mendelsohn, J.; Valade, J. J. Organomet. Chem. 1968, 11, 97. (b) Marshall, J. A.; Gung, W. Y. Tetrahedron Lett. 1989, 30, 2183. (c) Takuwa, A.; Kanaue, T.; Yamashita, K.; Nishigaichi, Y. J. Chem. Soc., Perkin Trans. 1 1998, 1309.

27. (a) Kumamoto, H.; Shindoh, S.; Tanaka, H.; Itoh, Y.; Haraguchi, K.; Gen, E.; Kittaka, A.; Miyasaka, T.; Kondo, M.; Nakamura, K. T. Tetrahedron 2000, 56, 5363.

28. Generation and cycloaddition of azomethine ylides from a-metalloamides or ametallothioamides via demetallation of imminium salts methods have been reported. For examples see: (a) Pearson, W. H.; Dietz, A.; Stoy, P. Org. Lett. 2004, 6, 1005. (b) Tsuge, O.; Hatta, T.; Shinozuka, M.; Tashiro, H. Heterocycles 2001, 55, 249. (c) Tsuge, O.; Hatta, T.; Tashiro, H.; Kakura, Y.; Maeda, H.; Kakehi, A. Tetrahedron 2000, 56, 7723. (d) Pearson, W. H.; Stoy, P.; Mi, Y. J. Org. Chem. 2004, 69, 1919. (e) Pearson, W. H.; Clark, R. B. Tetrahedron Lett. 1999, 40, 4467. (f) Pearson, W. H.; Mi, Y. Tetrahedron Lett. 1997, 38, 5441. (g) Vedejs, E.; West, F. G. Chem. Rev. 1986, 86, 941. (h) Padwa, A.; Haffmanns, G.; Tomas, M. J. Org. Chem. 1984, 49, 3314. (i) Padwa, A.; Haffmanns, G.; Tomas, M. Tetrahedron Lett. 1983, 24, 4303. (j) Vedejs, E.; West, F. G. J. Org. Chem. 1983, 48, 4773.

29. References on nitrile ylides or their equivalents: Hansen, H.-J.; Heimgartner, H. In 1,3Dipolar Cycloaddition Chemistry, Vol. 1; Padwa, A. Ed.; John Wiley \& Son: New York, 1984; pp. 177.

30. For a review, see: Grashey, R. In 1,3-Dipolar Cycloaddition Chemistry; Padwa, A. Ed.; John Wiley \& Sons: New York, 1984; Vol. 1, pp 733.

31. (a) Arrieta, A.; Carrillo, J. R.; Cossío, F. P.; Díaz-Oritz, A.; Gómez-Escalonilla, M. J.; De la Hoz, A.; Langa, F.; Moreno, A. Tetrahedron 1998, 54, 13167. (b) Sun, B.; Adachi, K.; 
Noguchi, M. Synthesis 1997, 53. (c) Sun, B.; Adachi, K.; Noguchi, M. Tetrahedron 1996, 52, 901. (d) Noguchi, M.; Yamada, K. Synthesis 1993, 145. (e) Noguchi, M.; Kiriki, Y.; Tsuruoka, T.; Mizui, T.; Kajigaeshi, S. Bull. Chem. Soc. Jpn. 1991, 64, 99. (f) Kanemasa, S.; Tomoshige, N.; Wada, E.; Tsuge, O. Bull. Chem. Soc. Jpn. 1989, 62, 3944. (g) Grigg, R.; Dowling, M.; Jordan, M. W.; Sridharan, V.; Thianpatanagul, S. Tetrahedron 1987, 43, 5873. (h) LeFevre, G.; Hamelin, J. Tetrahedron Lett. 1978, 19, 4503. (i) Grigg, R.; Kemp, J.; Thompson, N. Tetrahedron Lett. 1978, 19, 2827.

32. Oppolzer, W. Tetrahedron Lett. 1972, 17, 1707.

33. (a) Farina, P. R.; Tieckelmann, H. J. Org. Chem. 1975, 40, 1070. (b) Eicher, T.; Hünig, S.; Nikolaus, P. Chem. Ber. 1969, 102, 3176. (c) Eicher, T.; Hünig, S.; Hansen, H.; Nikolaus, P. Chem. Ber. 1969, 102, 3159. (d) Eicher, T.; Hünig, S.; Hansen, H. Chem. Ber. 1969, 102, 2889.

34. Challis, B. C.; Challis, J. A. In Supplement F: The chemistry of amino, nitroso and nitro compounds and their derivatives; Patai, S., Ed.; John Wiley and Sons: New York, 1982; Chapter 26.

35. Eckell, A.; George, M. V.; Huisgen, R.; Kende, A. S. Chem. Ber. 1977, 110, 578.

36. Kost, A. K.; Grandberg, I. I. In Advances in Heterocyclic Chemistry; Katritzky, A. R., Boulton, A. J., Eds.; Academic Press: London, 1966; pp 347. 